\title{
Enrichment a Study of Structural, Optical and Dielectric Properties of Mowiol 4-88 (Pva) Filled Zno Nanocomposites
}

\author{
Sahebagouda JAMBALADINNI ${ }^{1,2, *}$ and Jeddu Sadashiva BHAT ${ }^{3}$ \\ ${ }^{I}$ Department of Physics, Karnatak University, Dharwad 580003, India \\ ${ }^{2}$ Department of Physics, Government Engineering College, Huvina Hadagali 583219, India \\ ${ }^{3}$ Indian Institute of Information Technology, Surat 395007, India
}

('Corresponding author's e-mail: gouda321@gmail.com)

Received: 14 March 2021, Revised: 29 April 2021, Accepted: 7 May 2021

\begin{abstract}
The use of $\mathrm{ZnO}$ nanoparticles in the fabrication of PVA (Mowiol 4-88) nanocomposites with different ' $x$ ' filling compositions through solvent casting technique leading to the enrichment of the host's physical properties is presented. The sol-gel approach synthesizes Zinc Oxide ( $\mathrm{ZnO})$ nanoparticles. The formation of $\mathrm{ZnO}$ nanoparticles of size $100 \mathrm{~nm}$ was confirmed through X-ray powder diffraction (XRD) and Field Effect Scanning Electron Microscope (FESEM) techniques. The XRD technique determines the appearance of nanocomposites and their structural properties. The improvement in filling concentration enhances the particle size up to $150 \mathrm{~nm}$ and percentage crystallinity by $41 \%$ for optimum filler composition. The FTIR spectra demonstrate $\mathrm{ZnO}$ nanofillers' binding with $\mathrm{OH}$ group of host Mowiol 488 through intra or inter hydrogen bonding leading to a complex conformation. The optical studies indicate a decrease in the energy gap with the rise in filler composition up to $15 \mathrm{wt} \%$, and frequencydependent dielectric constant characterization shows the enhancement in the dielectric constant with an optimum filling concentration $15 \mathrm{wt} \% \mathrm{ZnO}$ nanofillers. FESEM image confirms homogenous distribution and complex particle size of incorporated $\mathrm{ZnO}$ nanoparticles in the PVA matrix.
\end{abstract}

Keywords: Nanoparticles, Fillers, Nanocomposites, PVA, ZnO, Composites, Dielectric studies

\section{Introduction}

Recently, polymeric materials are extensively used all over the world for fulfilling domestic and industrial requirements. These polymers are nonconductors, and filling these polymers with nanoparticles enhances their performance in the form of polymer nanocomposites [1-3]. The incorporated nanoparticles form an ex-situ polymerization with host polymer due to ion transfer, enhancing the polymer nanocomposites' structural, optical and dielectric properties. Thus, nanocomposites' development is significant and may find many potential implications in diverse fields such as light-emitting products, batteries, electromagnetic shielding, and other practical applications [4-8]. Amongst many host polymers, Polyvinyl Alcohol (PVA) (Mowiol 4-88) has outstanding properties such as chemical resistance, water solubility, and biodegradability [9-12]. Former works exposed that the PVA polymer can efficiently guard the nanoparticles against aggregation [13,14]. Thus, a homogenous distribution of nanoparticles is easily possible in the PVA matrix to achieve complex formation networks. Many hydroxyl groups on PVA's carbon backbone allow hydrogen bonding with hydrogen bond acceptor atoms in the reinforcing process, making it an ideal host material for synthesising polymer nanocomposites with various fillers. Apart from these, PVA is a gifted candidate to be used as a dielectric layer in electronic devices due to its appropriate properties such as low leakage current, high dielectric permittivity, easily processable, and good filmforming properties [15]. 
Filling the PVA with appropriate nanoparticles by various preparation techniques has enhanced the features of host polymeric materials [16]. Zinc oxide $(\mathrm{ZnO})$ nanoparticles have versatile properties such as extraordinary Young's modulus, tensile strength, outsized theoretical specific surface area, almost transparent, and excellent conductivity $[17,18]$. These $\mathrm{ZnO}$ nanoparticles are filled inside the PVA matrix via the ex-situ technique. In the present study, PVA filled with $\mathrm{ZnO}$ nanocomposites are prepared by a cost-effective solvent casting method. PVA (Mowiol 4-88) is a hydrophilic polymer that might absorb water from the atmosphere, affecting its physical properties. Thus, the prepared PVA nanocomposites are stored in a vacuum desiccator and used for further characterisation. The prepared PVA:(x)ZnO nanocomposites are further characterized by XRD, FTIR, UV visible, dielectric, and SEM techniques.

\section{Materials and methods}

\section{Synthesis of $\mathrm{ZnO}$ nanoparticles}

To get $\mathrm{ZnO}$ nanoparticles, the solution of Zinc nitrate hexahydrate $\left(\mathrm{Zn}\left(\mathrm{NO}_{3}\right)_{2} \quad 6 \mathrm{H}_{2} \mathrm{O}\right)$ (Sigma Aldrich, Germany) mixed with $350 \mathrm{~mL}$ of distilled water was stirred first for $1 \mathrm{~h}$ at $300 \mathrm{rpm}$. This solution was then treated with $25 \%$ ammonia until the resolution turbid turns to dry. The resulting precursor solution was refluxed under vigorous stirring for $4 \mathrm{~h}$ to yield the $\mathrm{ZnO}$ nanoparticles. The settled stock is subjected to centrifugation and continuously washed until the filtrate shows a neutral $\mathrm{pH}$ value. The cleaned substrate is then collected and dried in air at $400{ }^{\circ} \mathrm{C}$ for $4 \mathrm{~h}$ resulting in $\mathrm{ZnO}$ nanopowder [19].

Synthesis of PVA:(x)ZnO nanocomposites

To prepare PVA:(x)ZnO nanocomposites, 7 gm of Polyvinyl alcohol (Mowiol 4-88) having a molecular weight $\mathrm{Mw}=31000$ and molar percentage hydrolysis $86.7-88.7 \%$ were mixed with $80 \mathrm{~mL}$ of deionized water. The mixture was continuously stirred at $300 \mathrm{rpm}$ for $1 \mathrm{~h}$ while maintaining the temperature at $900{ }^{\circ} \mathrm{C}$. The pure PVA solvent was then divided into 8 equal parts, and for each position, the synthesized $\mathrm{ZnO}$ nanoparticles were filled for different filling concentrations $\mathrm{x}=0,1,5,7.5,10,14$ and $15 \%$, respectively. Further, $\mathrm{ZnO}$ nanofillers inside the PVA solvent were distributed uniformly using a probe ultrasonicator for $10 \mathrm{~min}$. After proper dispersion of the $\mathrm{ZnO}$ nanofiller, the PVA was casted in the petri dish to develop the desired nanocomposites. Thus, PVA:(x)ZnO nanocomposites of about 160 $175 \mu \mathrm{m}$ thickness was obtained.

\section{Material characterization}

The thickness of the nanocomposite films was determined by the DektaK stylus profilometer (Bruker). The average thickness of the nanocomposite films was about $170 \mu \mathrm{m}$. The semi-crystal structural investigations were done employing $3^{\text {rd }}$ generation Empyrean, Malvern Panalytical Multipurpose X-ray Diffractometer. Structural bonding and complex formation were analyzed using FTIR spectroscopy performed by $\mathrm{KBr}$ pelleting through Varian Excalibur FTIR spectrometer, in the range of $500-4000 \mathrm{~cm}^{-1}$ with 50 scans and resolution of $2 \mathrm{~cm}^{-1}$. Optical properties related to the estimation of the energy gap were evaluated by using Shimadzu UV visible Spectrometer. The frequencydependent dielectric parameters and capacitance were determined using the Keithley 4200-SCS parameter analyzer at room temperature in the applied frequency range from $1 \mathrm{kHz}$ to $1 \mathrm{MHz}$. The structural morphology and compositional features were studied by Scanning electron microscopy (SEM) EVO 18 model with ALTO 1000 cryo attachment.

\section{Results and discussion}

XRD studies of pure ZnO and PVA/(x)ZnO nanocomposites

The XRD spectra of PVA filled $\mathrm{ZnO}$ nanocomposites for various composition concentration is shown in Figure 1. The intense peaks at $2 \theta=32.32,35.17,36.72,49,57,66,69.32,70.46$ and 74.17 degrees (JCPDS ICDD card NO. 05-0664) indicates the presence of ZnO nanofillers in the PVA composites. The observed intense broad peaks at 19 to 20 degrees represent the presence of PVA 
molecules. Figure 1 shows the amplitude of the PVA peaks enhanced up to $15 \mathrm{wt} \%$, signifying the rise in crystalline parameters. This happens because the PVA molecule binds the $\mathrm{ZnO}$ nanofillers by entangling the fillers and enhancing the complex particle formation. Besides these, the peaks of PVA change towards the lower angle of XRD spectra with the rise in $\mathrm{ZnO}$ filler level suggest the growth of crystalline parameters in the composite. The upswing in crystalline parameters endorses that the incorporated $\mathrm{ZnO}$ nanofiller gets linked with inter/intra hydrogen bonding to occupy the inter-terrestrial sites of mowiol 4-88 (PVA) molecule, thereby forming a complex. This nature is observed up to $\mathrm{x}=15 \mathrm{wt} \%$ filler concentration, and above this optimum filler concentration, the crystallinity reduces. The average crystallite sizes (D) of the filled $\mathrm{ZnO}$ are estimated using the formulation of Debye-Scherrer [20]

$\mathrm{D}=\frac{\mathrm{k} \lambda}{\beta \cos \theta}$,

where $\mathrm{k}$ is a constant having value equal to 0.9 and depends on the shape of the crystal and crystallographic planes, $\lambda$ the wavelength of x-rays, $\beta$ the full width at half maximum of X-ray profile and $\theta$ is the Bragg angle. The percentage crystallinity of the PVA:(x)ZnO polymeric compound is calculated using the relation [21],

$\%$ Crystallinity $=\frac{\text { (total area of crystalline peaks) }}{\text { (the full size of all peaks) }}$

The average inter-crystallite separation (R) inside the PVA:(x)ZnO nanocomposites are determined using the relation,

$\mathrm{R}=\frac{5 \lambda}{8 \sin \theta}$

where $\lambda$ is the wavelength of $x$-ray radiation and $\theta$ is the diffraction angle. The microstrain (ع) created in the $\mathrm{ZnO}$ nanofiller inside the PVA matrix is determined using [22],

$\varepsilon=(\beta \cos \theta / 4)$

The dislocation density of nanofiller $(\delta)$ produced in PVA matrixes are intended using [23],

$\delta=1 / \mathrm{D} 2$

The crystalline parameters for various filler compositions are given in Table 1. The variation found in Table 1 represents the structural regularity that exists due to $\mathrm{ZnO}$ nanofiller concentration inside the PVA main chain. These crystalline parameters are responsible for the reduced energy gap and high electric conductivity of PVA:(x) $\mathrm{ZnO}$ nanocomposites. 


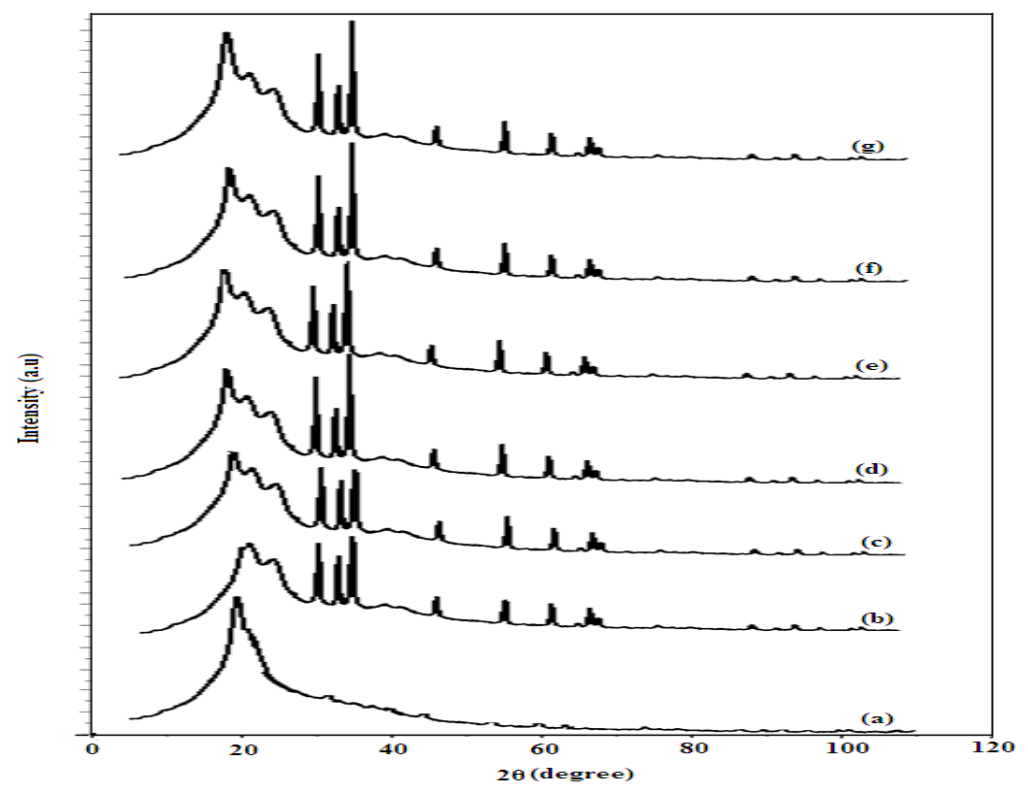

Figure 1 XRD analysis of nanocomposite PVA:(x)ZnO for (a) $\mathrm{x}=0 \mathrm{wt} \%$, (b) $\mathrm{x}=1 \mathrm{wt} \%$, (c) $\mathrm{x}=5 \mathrm{wt} \%$, (d) $x=7.5 w t \%$, (e) $x=10 w t \%$, (f) $x=14 w t \%$ and (g) $x=15 w t \%$.

Table 1 Crystalline parameters of PVA:(x)ZnO nanocomposites for ' $\mathrm{x}$ ' nanofiller concentration.

\begin{tabular}{|c|c|c|c|c|c|c|}
\hline Sl.No & $\begin{array}{c}\text { Sample } \\
\text { Wt\% }\end{array}$ & $\begin{array}{l}\text { Percentage of } \\
\text { Crystallinity }\end{array}$ & $\begin{array}{c}\text { Average } \\
\text { crystallinity } \\
\text { size D }(\mathrm{nm}) \\
\end{array}$ & $\begin{array}{c}\text { Average inter- } \\
\text { crystalline } \\
\text { separation } R(\AA)\end{array}$ & $\begin{array}{l}\text { Micro strain } \\
\text { (E) } \times 10^{-3}\end{array}$ & $\begin{array}{c}\delta \\
\left(10^{13} \text { lines } / \mathrm{m}^{2}\right)\end{array}$ \\
\hline 1 & Pure $\mathrm{ZnO}$ & 93.56 & 100.11 & - & 0.638 & 9.978 \\
\hline 2 & $0 \mathrm{wt} \%$ & 52.85 & 2.59 & 5.72 & 13.54 & 14907.4 \\
\hline 3 & $1 \mathrm{wt} \%$ & 56.95 & 121.17 & 5.37 & 1.632 & 6.810 \\
\hline 4 & $5 \mathrm{wt} \%$ & 57.12 & 125.16 & 5.21 & 1.597 & 6.383 \\
\hline 5 & $7.5 \mathrm{wt} \%$ & 62.31 & 132.50 & 5.13 & 1.492 & 5.695 \\
\hline 6 & $10 w t \%$ & 63.07 & 143.23 & 4.94 & 1.232 & 4.874 \\
\hline 7 & $14 \mathrm{wt} \%$ & 64.90 & 147.12 & 4.82 & 1.195 & 4.620 \\
\hline 8 & $15 w t \%$ & 65.73 & 148.53 & 4.38 & 0.983 & 4.532 \\
\hline
\end{tabular}

\section{SEM and EDS studies}

The SEM is often used to measure $\mathrm{ZnO}$ nanofiller's effect on phase separations and interfaces in the host PVA matrix. SEM micrographs of PVA:(x)ZnO nanocomposites are shown in Figure 2. These micrographs reveal the homogeneous distribution of $\mathrm{ZnO}$ nanofillers in the PVA matrix. The average particle size obtained from SEM is comparable to that estimated from the XRD results. The microstructural variation between PVA and Zno nanofillers interface is due to ZnO's particle size and complex formation between $\mathrm{ZnO}$ nanoparticles in the fundamental PVA polymer matrix. The homogenous distribution of $\mathrm{ZnO}$ nanofillers in the PVA matrix observed in SEM image also enhances the microstructural properties of PVA:ZnO nanocomposites. The SEM morphology of $\mathrm{ZnO}$ nanoparticles are irregular flakes.

Figure 3 represents the chemical properties and homogeneous percentage analysis of PVA filled with $\mathrm{ZnO}$ polymer composite film and investigated using the energy dispersive X-ray analysis (EDS). To 
analyze the EDS spectra, the filled polymer nanocomposite films were sputtered blanketed by gold particles to decry the artifacts generated by charging on the film's top surface. A continuum of synthesized $\mathrm{ZnO}$ nanoparticles taken from EDS supports $\mathrm{ZnO}$ 's existence in the polymeric nanocomposites area, as seen in Figure 3.

SEM accomplished elemental mapping of $\mathrm{ZnO}$ nanofillers to confirm the dispersion of $\mathrm{Zn}, \mathrm{C}$ and $\mathrm{O}$ in the surface of the PVA nanocomposites. Figure 4 displays the elemental mapping in various colours such as $\mathrm{O}$ (green), $\mathrm{Zn}$ (blue), and $\mathrm{C}$ (red), respectively. The elemental mapping also signifies the homogenous distribution of $\mathrm{ZnO}$ nanofillers in the PVA nanocomposites.

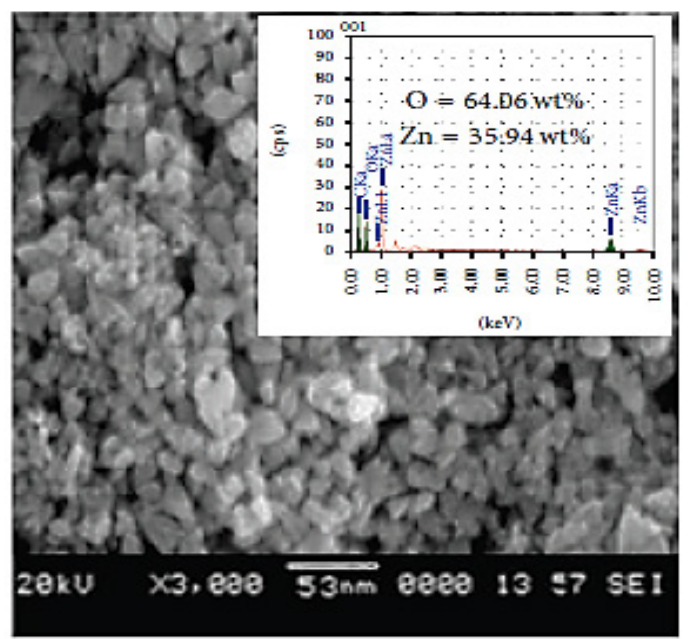

(a)

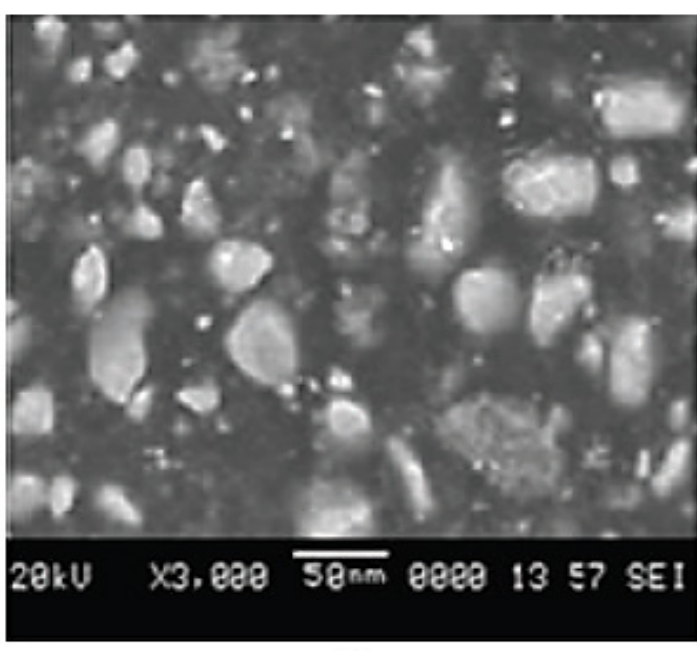

(b)

Figure 2 SEM images of (a) pure $\mathrm{ZnO}$ and (b) PVA filled with $\mathrm{x}=15 \mathrm{wt} \%$ of $\mathrm{ZnO}$ nanocomposites.

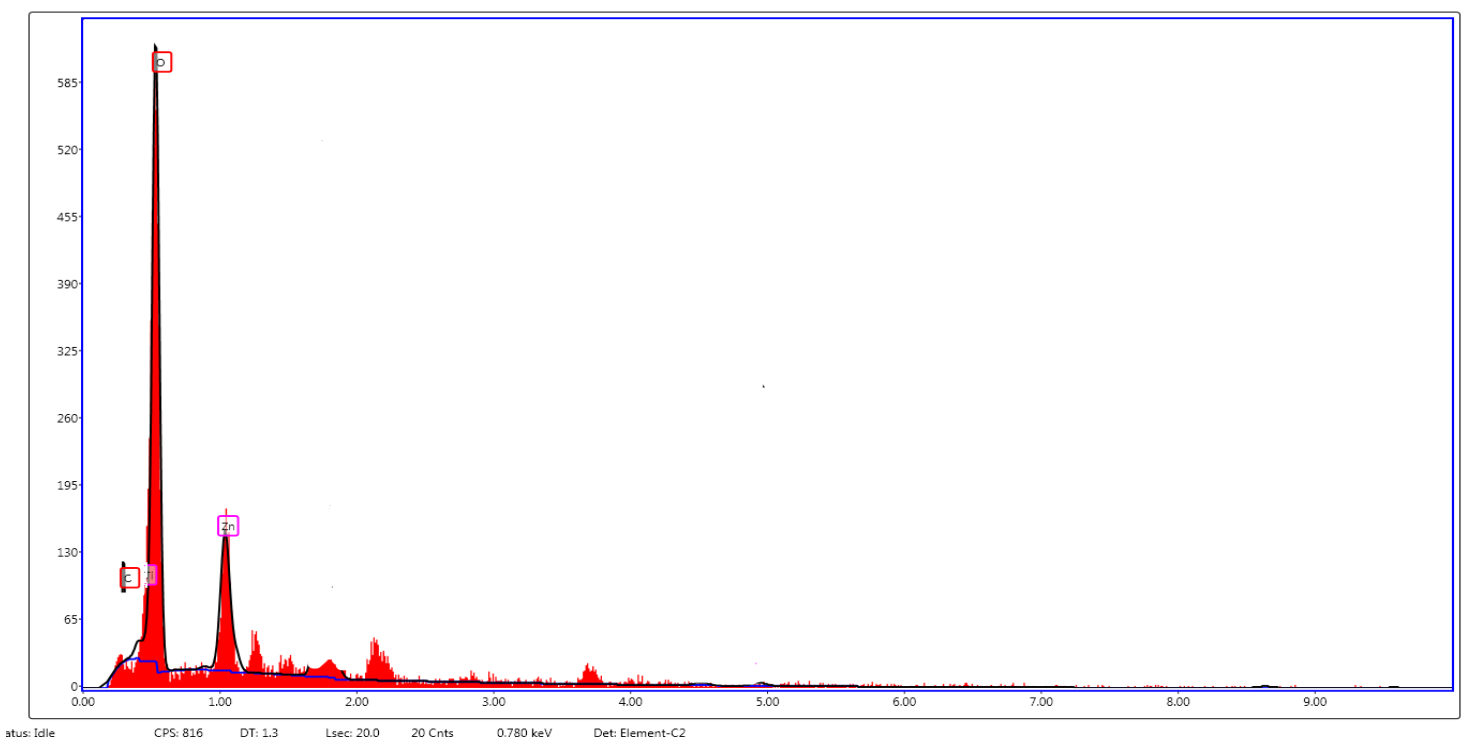

Figure 3 EDS spectra of $\mathrm{ZnO}$ filled PVA nanocomposites for $\mathrm{x}=15 \mathrm{wt} \%$ filler concentration. 

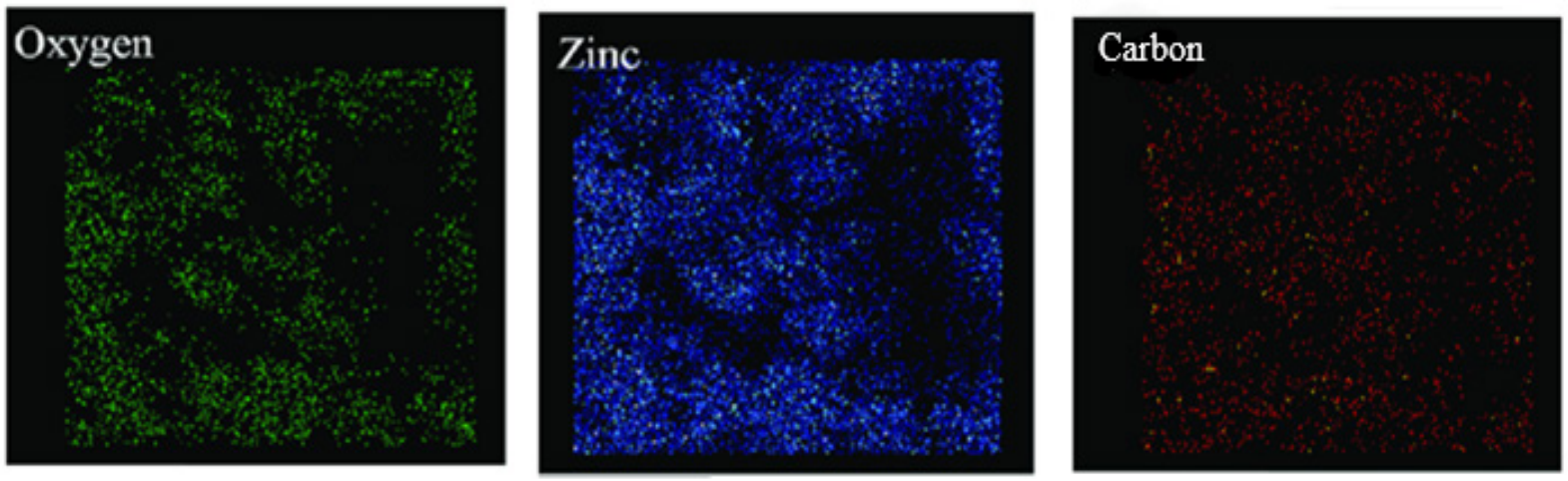

Figure 4 Elemental mapping of fillers present in the PVA matrix for $\mathrm{x}=15 \mathrm{wt} \%$.

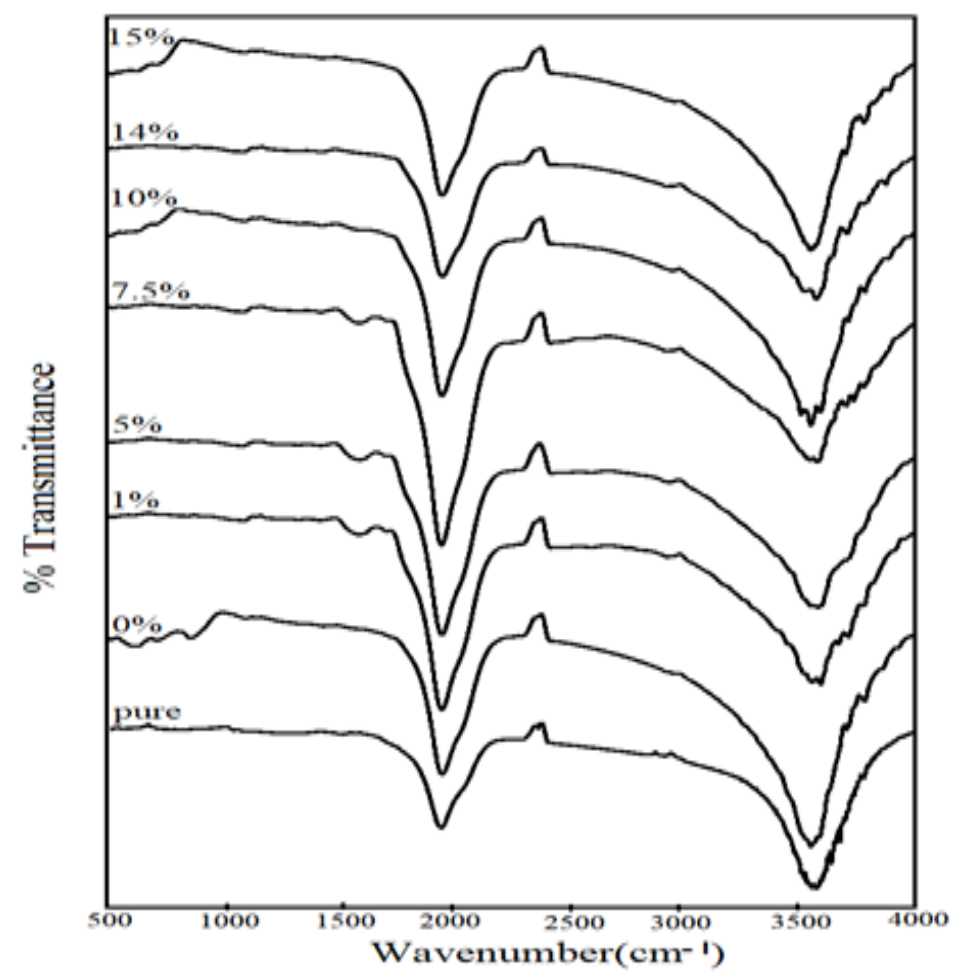

Figure 5 FTIR spectra of PVA:(X)ZnO composites for ' $\mathrm{x}$ ' filler concentration.

\section{FTIR analysis of $\mathrm{ZnO}$ doped PVA nanocomposites}

Figure 5 shows the FTIR spectra of PVA:(x)ZnO for unfilled and filled nanocomposites. The extreme broadband detected in the wavenumber range $3498.23 \mathrm{~cm}^{-1}$ reflects the $\mathrm{O}-\mathrm{H}$ group of the PVA main chain [24,25]. The rise in filler concentration shifts in the O-H group of PVA peak to lower wavenumber due to the strong intra/intra hydrogen bonding with added $\mathrm{ZnO}$ nanofillers. This indulges the PVA main chain in entangling the hydroxyl group with $\mathrm{ZnO}$ nanofillers forming a stable complex. The peak present near $3000 \mathrm{~cm}^{-1}$ represents the $\mathrm{CH}_{2}$ group of the PVA:(x)(ZnO) nanocomposites. The peak at $1423 \mathrm{~cm}^{-1}$ is due to $\mathrm{C}-\mathrm{C}$ stretching, and the peak at $580 \mathrm{~cm}^{-1}$ represents the $\mathrm{Zn}-\mathrm{O}$ stretching in the 
nanocomposites. Apart from these, the substantial shift of $\mathrm{C}-\mathrm{O}$ and $\mathrm{C}-\mathrm{O}-\mathrm{C}$ stretching vibrations of host PVA confirm the interaction of the $\mathrm{O}-\mathrm{H}$ group of PVA and added nanofillers [25]. The intense peaks found at $1850 \mathrm{~cm}^{-1}$ signifies the $\mathrm{C}=\mathrm{O}$ group entangled at this point, comprehending the complete anhydride in a symmetric or asymmetric stretching motion inside the nanocomposite material. The peak shifting towards the lower side of the wavenumber in FTIR spectra shows the enhancement in molecular mass. This happens because the vibrational frequency is inversely proportional to vibrating molecule mass. Thus, the random coils of PVA entangle with the added nanofillers creating a dense, complicated molecular packing, thereby enhancing the crystalline properties of PVA:(x)ZnO nanocomposites with the rise in filler concentration.

\section{UV-visible spectroscopy studies}

The UV Visible spectrum of nanocomposites sample concentrations as shown in Figure 6 displays the absorption spectra of pure PVA (Mowiol 4-88) and PVA distributed with ZnO nanofillers. Mowiol 488 firmly absorbs the radiation within the $200-400 \mathrm{~nm}$ wavelength region [26,27]. Figure 3 also indicates the change for various amounts of filled PVA samples in both absorption bands and the bands' edges to higher wavelengths with varying absorption intensities. These absorption bands' changes provide an understanding of the nature of inter and intramolecular hydrogen bonding between $\mathrm{Zn}$ ions and neighbouring PVA main chain $\mathrm{OH}$ groups. The observed enhancement found in the absorption is mainly due to increased concentration of $\mathrm{ZnO}$ nanofillers causing the hydrogen bonding with host PVA. Apart from these, the shift observed in the filled PVA nanofilms absorption edge is essentially due to the difference in crystalline parameters, which shifts the distance in the energy band.

The expression of classical Tauc's correlates the absorption co-efficient $(\alpha)$ and the optical band distance (Eg). From the UV/visible spectra, the optical energy band gap is evaluated employing frequency-dependent absorption co-efficient specified by Mott and Davis to transfigure the spectra into Tauc's plots $[28,29]$. The profound linear behaviour of the plotted curve of the absorption coefficient and photon energy $(\alpha h v) 0.5$ versus the photon energy $(h v)$ represents the indirect allowed transition. Thus, the optical energy bandgap (Eg) values of the filled composites are evaluated by extrapolating the linear portion of the curve to a point $(\alpha h v) 0.5=0$ (Figure 7). Thus, the indirect transition can be anticipated among the valence as well as conduction bands.

Table 2 shows the values of Eg intended for various filler levels of the nanocomposite samples. Table 2 also articulates the enhancement in filler concentration, which deteriorates the band gap value (Eg). These decreases in the Eg are attributable to local cross-linking occurring in the interior of the composite polymer's non-crystalline phase. This improvement in local cross-linking also improves the ordering degree in the PVA main chain, consequently reducing the energy gap parameters. Similar findings are found in XRD spectra, suggesting $\mathrm{ZnO}$ nanofillers' association with the PVA main chain entangles through intra/intermolecular hydrogen bonding. This dynamic structure induces microstructural variation that exists between both the nanofiller as well as underlying Mowiol matrix. This improvement in microstructural conditions results in a reduction in the energy band gap values of polymeric nanocomposites. The low optical energy gap of PVA:(x)ZnO nanocomposites material in future application in fabricating UV filters or UV protectors in paints, textiles and the plastic industry. 


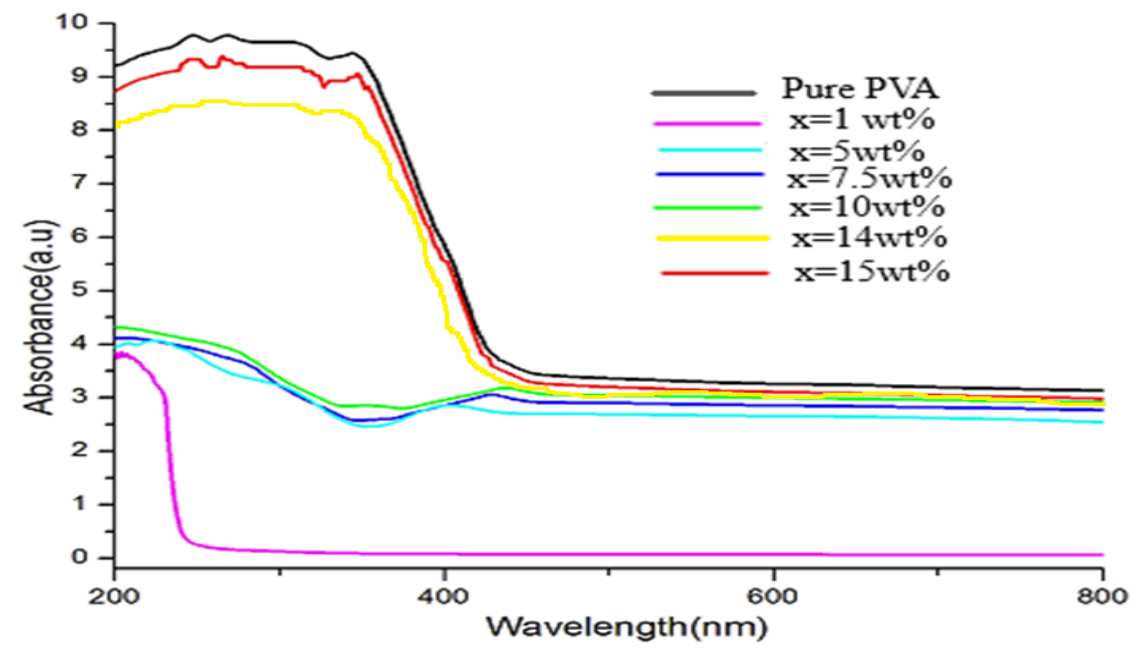

Figure 6 UV-Visible spectra of pure and ZnO incorporated PVA for different 'x' filler concentration.

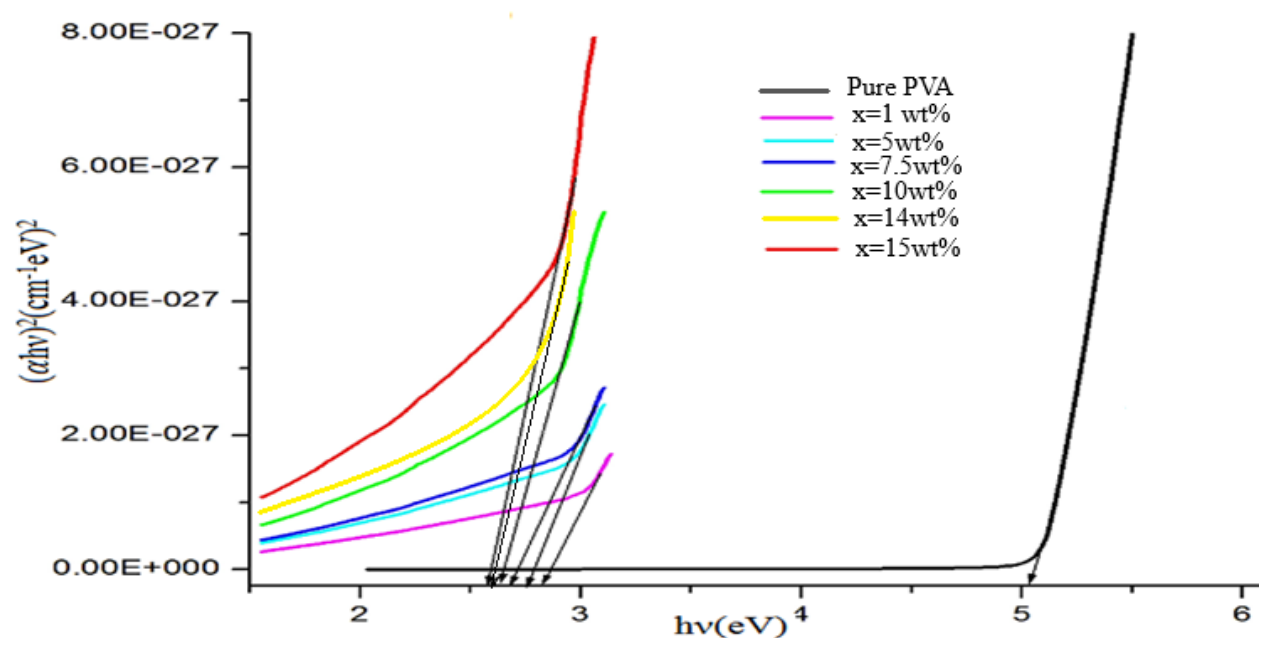

Figure 7 Optical energy band gap values of pure and $\mathrm{ZnO}$ incorporated PVA nanocomposites for different ' $x$,' filler concentration.

Table 2 Variation of optical band gap (Eg) for different $\mathrm{ZnO}$ filler wt $\%$ in PVA:(x)ZnO nanocomposites.

\begin{tabular}{ccc}
\hline Sl. No & Sample (wt\%) & Energy Gap (eV) \\
\hline 1 & 0 & 5.08 \\
2 & 1 & 2.88 \\
3 & 5 & 2.79 \\
4 & 7.5 & 2.76 \\
5 & 10 & 2.70 \\
6 & 14 & 2.67 \\
7 & 15 & 2.62 \\
\hline
\end{tabular}




\section{DC conductivity analysis}

The variation of DC conductivity of PVA:(x) $\mathrm{ZnO}$ nanocomposite for different filler wt $\%, \mathrm{x}=0,1$, $5,7.5,10,14$ and $15 \%$ is as tabulated in Table 3. It is noticed that the DC conductivity of these nanocomposites improves with increasing filler percentage. As discussed in XRD data, the rise in crystalline constraints promotes the enhancement in DC conductivity of PVA:(x)ZnO nanocomposites. The improved crystallinity decreases the height of the barrier between the trapping sites, thus promoting the complexes to transfer the charges [30]. Reducing the barrier height creates a direct path through amorphous PVA regions, which raises the DC conductivity.

Table 3 DC conductivity values of PVA doped with $\mathrm{ZnO}$ nanofillers.

\begin{tabular}{|c|c|c|c|}
\hline SI No & $\begin{array}{c}\mathrm{ZnO} \\
(\mathbf{w t} \%)\end{array}$ & Resistance( $(\Omega)$ & Conductivity ( $\sigma$ in $\mathrm{S} / \mathrm{cm}$ ) \\
\hline 1 & 0 & $9.5864 \times 10^{6}$ & $1.0419 \times 10^{-11}$ \\
\hline 2 & 1 & $9.3476 \times 10^{5}$ & $4.1921 \times 10^{-10}$ \\
\hline 3 & 5 & $8.264 \times 10^{5}$ & $7.8063 \times 10^{-10}$ \\
\hline 4 & 7.5 & $6.648 \times 10^{5}$ & $8.914 \times 10^{-10}$ \\
\hline 5 & 10 & $3.895 \times 10^{5}$ & $11.388 \times 10^{-10}$ \\
\hline 6 & 14 & $5.723 \times 10^{4}$ & $2.460 \times 10^{-9}$ \\
\hline 7 & 15 & $2.845 \times 10^{4}$ & $3.702 \times 10^{-9}$ \\
\hline
\end{tabular}

\section{Dielectric studies}

It is well known that for the fabrication of flexible antennas and EMI absorbers, the dielectric properties of the material must be in the range of megahertz. The variation of dielectric constant $\left(\varepsilon^{\prime}\right)$ and dielectric loss $\left(\varepsilon^{\prime \prime}\right)$ with the frequency is shown in Figures $8(\mathbf{a})$ and $\mathbf{8}(\mathbf{b})$ for different $\mathrm{ZnO}$ filler concentrations of $\mathrm{ZnO}$ in nanocomposites. It is observed that the permittivity is higher at lower frequencies, and the real part of permittivity declines as the lower frequency enhances. This condition is seen for polar materials. Further, the higher dielectric values at the lower frequency region are mainly attributable to the interface effect. The molecular motions are restricted at a lower frequency and make the dipole molecule align itself in the applied field's direction. The retrograde movement in dielectric values usually occurs at a higher frequency because of the electrical relaxation mechanism that charge carriers add to each other within isolated states. Thus, integrating the $\mathrm{ZnO}$ nanofillers in the PVA matrix develops the number of dispersed charge carriers leading to higher electrical conductivity [31,32]. The low dielectric constant of PVA:(x)ZnO nanocomposites at high frequency are used as tunable interlayer dielectric, which reduces resistance-capacitance (RC) time delays, fast signal propagation system, high frequency optical interconnects and microdevices. 

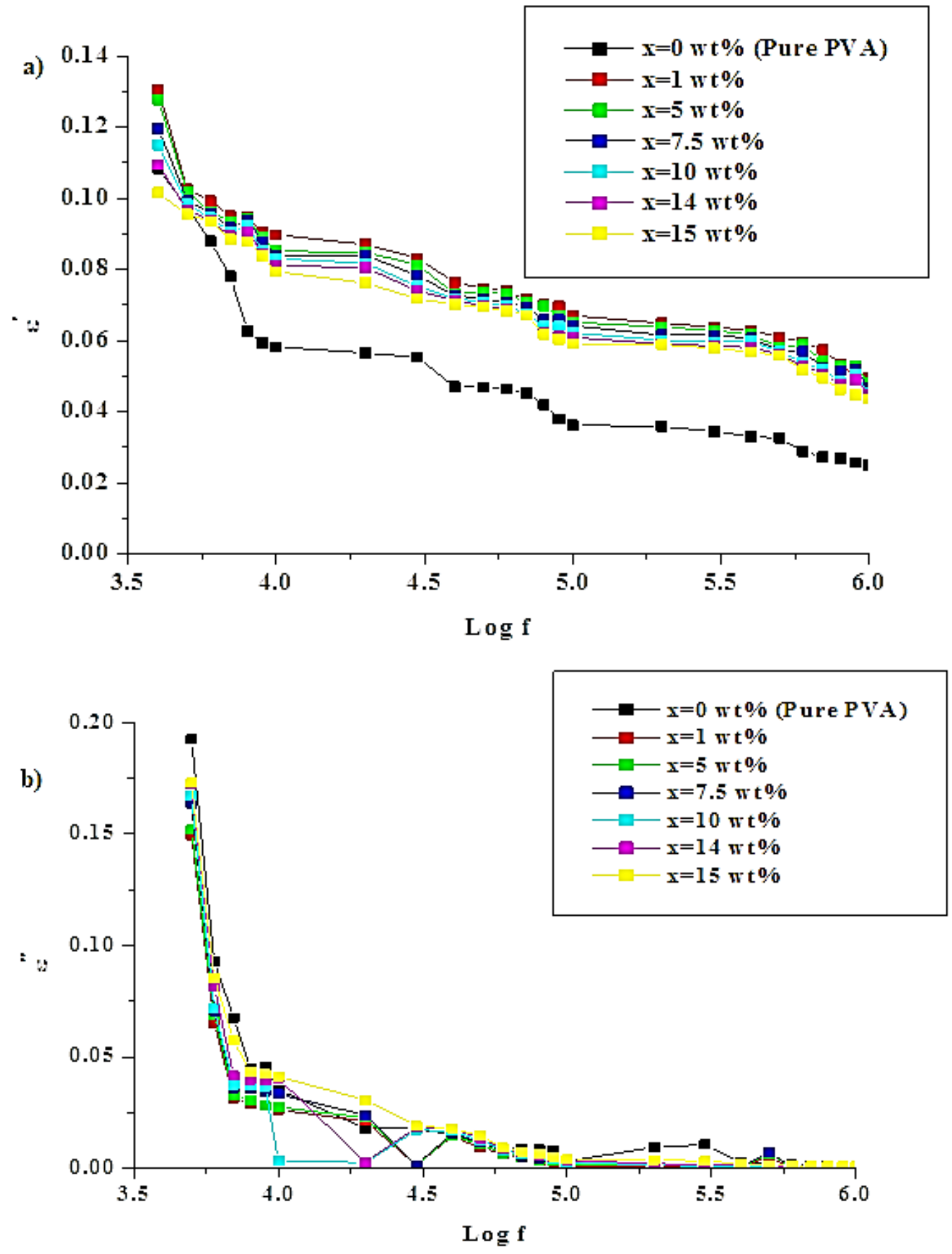

Figure 8 (a) Deviation of dielectric constant $(\varepsilon)$ and (b) dielectric loss $(\varepsilon ")$ with frequency for diverse ' $\mathrm{x}^{\prime}$ $\mathrm{ZnO}$ filler level. 
Figure 8(b) signifies a drop in dynamic dielectric values with increased frequency for various ' $\mathrm{x}$ ' filler concentrations in PVA:(x)ZnO nanocomposites. The complex dielectric values declines at a higher frequency range are due to the transformation of free charge carriers bound to the PVA main chain. This usually occurs due to polarization of the dipole orientation and interfacial impacts of surface charge between the electrode and the surface of PVA:(x)ZnO polymeric films. On the other hand, the dielectric loss is also linked to ohmic electrical conduction, and filling $\mathrm{ZnO}$ nanoparticle into the PVA matrix regulates the actual and complex dielectric permittivity. This activity is primarily due to the involvement of electric charge and dipole configuration in PVA nanocomposites. Thus, these considerations lead to an overall improvement in PVA conductivity:(x)ZnO nanocomposites [33].

The correct approach that assesses the loss of power and direct and alternating voltage in electric isolation is called the dielectric loss factor (Tan $\delta$ ). This dielectric loss is due to polymer molecules' failure to endure the polarization procedure in the vicinity of the alternating applied electric field.

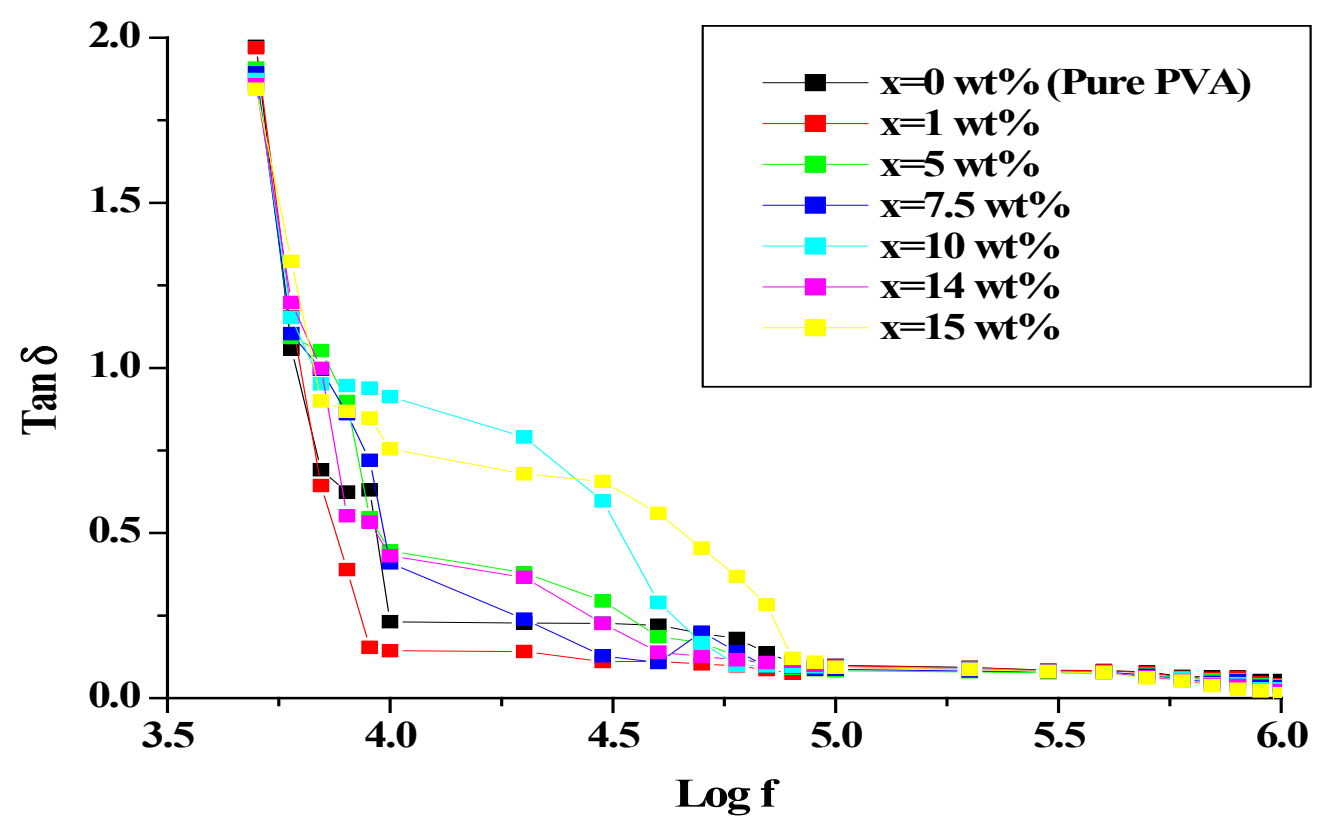

Figure 9 Variance of dielectric loss with a raise in $\mathrm{PVA} /(\mathrm{x}) \mathrm{ZnO}$ nanocomposites frequency for various nanoparticles 'x' filler level.

Figure 9 displays the tangent loss difference with an improvement in different ' $x$ ' filler levels of PVA:(x)ZnO nanocomposites. The existence of the tangent loss curve for specific $\mathrm{ZnO}$ nanofiller concentration indicates that the PVA:(x)ZnO nanocomposites, the relaxation, and non-relaxation dipoles are irreversible. The lower limit of 0.09305 tangent loss is identified for $\mathrm{x}=15 \mathrm{wt} \%$ filler level at 0.1 $\mathrm{MHz}$, and, at this point, the tangent loss reaches a plateau, commemorating the PVA nanocomposite behaves as lossless material [33,34]. Figure 9 signpost that this PVA:(x)ZnO nanocomposites can be used as a tunable dielectric material. In general, it can also be inferred that the $\mathrm{ZnO}$ nanofiller's existence in the Mowiol 4-88 host matrix will lessen the loss of energy and boost the electronic characteristics of nanocomposites. 


\section{Conclusions}

In conclusion, PVA filled with $\mathrm{ZnO}$ nanocomposites is developed by solvent casting method. The XRD analysis indicates crystallinity enhancement up to $\mathrm{x}=15 \mathrm{wt} \%$ filler level owing to charge exchange complexes formulated by intra and inter-molecular bonding with compressed molecular packing vanishing molecular motion. SEM and EDS illustrate $\mathrm{ZnO}$ nanofiller's systematic distribution and affirm their existence of $\mathrm{ZnO}$ in the PVA nanocomposite film. Thus, this PVA:(x)ZnO nanocomposites having dielectric properties in the range of megahertz finds usage in designing and fabrication of flexible antennas as well as EMI absorbers. The FTIR spectra shifts expose the complex interaction among Zn ion with PVA chain $\mathrm{OH}$ group using intra/inter-molecular hydrogen bonding. The UV-visible spectra show the ZnO-filled PVA by decreasing the rise in filler concentration and the energy gap value of $\mathrm{Eg}=2.62 \mathrm{eV}$ value for $\mathrm{x}=15 \mathrm{wt} \%$. The $\mathrm{DC}$ conductivity analyses confirm that the increase in concentration leads to increased DC conductivity. Dielectric measurements show that these fabricated polymeric composites are polar. The dielectric losses are observed prominent at low frequencies.

\section{References}

[1] RD Clark. Emerging applications for high K materials in VLSI technology. Materials 2014; 7, 2913-44.

[2] M Sharma and SK Tripathi. Photoluminescence study of CdSe nanorods embedded in a PVA matrix. J. Lumin. 2013; 135, 327-34.

[3] U Keirbeg and M Vollmer. Optical properties of metal clusters. Springer-Verlag, Berlin. 1995.

[4] Y Azizian. Dielectric properties of CdS-PVA nanocomposites prepared by the ultrasound-assisted method. Optoelectron. Aad. Mater. Rapid Comm. 2010; 4, 1655-8.

[5] JB Omajali, JG Bolivar and IP Mikheenko. Novel catalytically active $\mathrm{Pd} / \mathrm{Ru}$ bimetallic nanoparticles synthesized by Bacillus benzofurans. Sci. Rep. 2019; 9, 4715.

[6] JY Cheon, YO Kang, WH Park. Formation of Ag nanoparticles in PVA solution and catalytic activity of their electrospun PVA nanofibers. Fiber. Polym. 2015; 16, 840-9.

[7] EJ Shin, YH. Lee and SC Choi. Study the structure and processibility of the iodinated poly (vinyl alcohol). I. Thermal analyses of iodinated poly (vinyl alcohol) films. J. Appl. Polym. Sci. 2004; 91, 2407-15.

[8] ZH Mbhele, MG Salemane, CGCEV Sittert, JM Nedeljkovic, V Djokovic and AS Luyt. Fabrication and characterization of silver-polyvinyl alcohol nanocomposites. Chem. Mater. 2003; 15, 5019-24.

[9] ME Hasnaoui, MPF Graca, ME Achour and LC Costa. Electric modulus analysis of carbon black/copolymer composite materials. Mater. Sci. Appl. 2011; 2, 1421-6.

[10] GX Zou, JP Qu and XL Zou. Extruded starch/PVA composites: Water resistance, thermal properties, and morphology. J. Elastomer. Plast. 2008; 40, 303-16.

[11] J Zanela, JB Olivato, AP Dias, MVE Grossmann and F Yamashita. Mixture design applied for developing films based on starch, polyvinyl alcohol, and glycerol. J. Appl. Polym. Sci. 2015; 132, 42697.

[12] W Wang, H Zhang, Y Dai, H Hou and H Dong. Effects of low poly(vinyl alcohol) content on properties of biodegradable blowing films based on two modified starches. J. Thermoplast. Compos. Mater. 2015; 30, 1017-30.

[13] AN Ananth, S Umapathy, J Sophia, T Mathavan and D Mangalaraj. On the optical and thermal properties of in situ/ex situ reduced Ag NP's/PVA composites and its role as a simple SPR based protein sensor. Appl. Nanosci. 2011; 1, 87.

[14] M Ghanipour and D Dorranian. Effect of Ag-nanoparticles doped in polyvinyl alcohol on the structural and optical properties of PVA. J. Nanomater. 2013; 2013, 1.

[15] AEV Etten, ES Ximenes, LT Tarasconi, ITS Garcia, MMC Forte and H Boudinov. Insulating characteristics of polyvinyl alcohol for integrated electronics. Thin Solid Films 2014; 568, 111.

[16] X Tang and S Alavi. Recent advances in starch, polyvinyl alcohol-based polymer blends, nanocomposites and their biodegradability. Carbohydr. Polym. 2011; 85, 7-16. 
[17] S Kumar, B Krishnakumar, A Sobral and J Koh. Bio-based (chitosan/PVA/ZnO) nanocomposites film: Thermally stable photoluminescence material for removal of organic dye. Carbohydr. Polym. 2019; 205, 559-64.

[18] RG Hamid, PM Ferdos, P Hossein and MR Behrad. Synthesis of $\mathrm{ZnO}$ nanoparticles by precipitation method. Orient. J. Chem. 2015; 31, 1219-21.

[19] RNB Kumar, V Crasta, BM Praveen, M Kumar. Studies on structural, optical and mechanical properties of MWCNTs and $\mathrm{ZnO}$ nanoparticles doped PVA nanocomposites. Nanotech. Rev. 2015; 4, 457-67.

[20] P Debye and P Scherrer. Interferenzen a regellos orientierten Teilchen in Röntgenlicht. Phys. Z. $1916 ; 17,277-82$.

[21] LE Alexander. X-ray diffraction methods in polymer science. Wiley, Interscience, New York, 1969.

[22] GB Williamson and RC Smallman. Dislocation densities in some annealed and cold-worked metals from measurements on the X-ray Debye Scherrer spectrum. Phil. Mag. 1956; 1, 34-46.

[23] HM Zidan. Structural properties of $\mathrm{CrF}_{3}$ and $\mathrm{MnCl}_{2}$-filled poly (vinyl alcohol) films. J. Appl. Polym. Sci. 2003; 88, 1115-20.

[24] MS Selim, R Seoudi and AA Shabaka. Polymer-based films embedded with a high content of ZnSe nanoparticles. Mater. Lett. 2005; 59, 2650-4.

[25] Z Vilamova, Z Konvickova, P Mikes, V Holisova, P Mancik, E Dobrocka, G Kratosova and J Seidlerova. Ag-AgCl nanoparticles fixation on electrospun PVA fibres. Technol. Concept Progr. Sci Rep. 2019; 9, 15520.

[26] MA El-Ahdal. Radiation effect on the molecular structure of dyed poly (vinyl alcohol). Int. J. Polymer. Mater. 2000, 48, 17-28.

[27] KAMA El-Kader and SFA Hamied. Preparation of poly (vinyl alcohol) films with promising physical properties in comparison with commercial polyethylene film. J. Appl. Polym. Sci. 2002; 86, 1219-26.

[28] NF Mott and EA Devis. Electronic process in non-crystalline materials. $2^{\text {nd }}$ eds. Oxford University Press, Oxford, 1979.

[29] J Tauc. Optical properties of solids in Optical Properties of Solid. In: F Abeles (Ed.). p. 277, NorthHolland, Amsterdam, The Netherlands, 1972.

[30] S Mahendra, AK Tomara and S Kumar. Electrical conductivity and dielectric spectroscopic studies of PVA-Ag nanocomposite films. J. Alloy. Comp. 2010; 508, 406-11.

[31] NBR Kumar, V Crasta and BM Praveen. Dielectric and electric conductivity studies of PVA (Mowiol 10-98) doped with MWCNTs and WO3 nanocomposites films. Mater. Res. Express 2016; 3, 055012 .

[32] D Mardare and GI Rusu. Comparison of the dielectric properties for doped and un doped $\mathrm{TiO}_{2}$ thin films. J. Optoelectron. Adv. Mater. 2004; 6, 333-6.

[33] V Rao, PV Ashokan and MH Shridhar. Studies of dielectric relaxation and AC conductivity in cellulose acetate hydrogen phthalate-poly (methyl methacrylate) blends. Mater. Sci. Eng. A 2000; 281, 213-20.

[34] MS Tsai and TY Tseng. Effect of bottom electrodes on dielectric relaxation and defect analysis of (Ba0.47 Sr0. 53) $\mathrm{TiO}_{3}$ thin film capacitors. Mater. Chem. Phys. 1998; 57, 47-56. 